\section{Memórias de Pesquisa}

\title{
Telephone: Ensaio sobre a solidariedade feminina e a potencialidade a partir de movimentos miméticos
}

Miguel Antonio dos Santos Filho

Apontamentos iniciais

A breve discussão proposta aqui tem como objetivo refletir sobre a forma pela qual se apresenta, na trama do videoclipe Telephone, parceria entre as cantoras estadunidenses Lady Gaga e Beyonce no ano de 2010, um discurso e, principalmente, atuação da solidariedade feminina, ideia muito debatida historicamente pelas militantes de diferentes vertentes no feminismo. Produção da Streamline Records e da Interscop Records, com direção e coprodução entre Lady Gaga e o diretor sueco Jonas Arkelund, esse clip é a continuação da história presente também na videografia de Lady Gaga, para a canção Paparazzi, dirigida no ano anterior pelo mesmo diretor. Na referida produção de 2010 percebemos a vinculação entre Beyonce e Lady Gaga para cometerem o assassinato em torno do qual gira uma trama de solidariedade e apoio feminino entre as protagonistas. O ponto de análise sociológica se dá na medida em que podemos considerar essa produção audiovisual (o videoclipe em si) como uma materialidade que, ao transmitir uma ideia e permitir formas de tomada de consciência a partir de si - como assinala Hans Gumbretch (2010) - torna-se potente para pensarmos movimentos de mimesis que reproduzem expressões do real - neste caso, os discursos de militantes feministas sobre a solidariedade feminina e ao mesmo tempo se constitui por colaborar com processos comunicacionais, talvez pedagógicos, capazes de trazer para a realidade experienciável, material e cotidiana da vida, algumas considerações sobre formas de sociabilidades femininas de apoio mútuo e combate às expressões machistas contidas nas relações sociais.

Trago a ideia de solidariedade feminina, aqui, como uma expressão forte e presente em discursos feministas urbanos atuais - seja em blogs, canais virtuais, articulações de grupos em redes sociais, coletivos feministas etc. - que ambiciona propagar o espirito de apoio e cuidado mútuo entre mulheres, despertando a consciência sobre a importância da união entre as mesmas para combater as opressões machistas. Tais discussões estão presentes com muita expressão nos canais virtuais de comunicação e nos movimentos sociais, e foi mais nelas do que em produções acadêmicas sobre o tema, que me debrucei para entender os discursos produzidos, as representações e as construções possíveis sobre as ideias de solidariedade feminina ou de sororidade $e^{1}$ para as sujeitas que as vivenciam. 
A ideia de Sororidade (do latim clássico soror que significa irmã ou companheira e o sufixo "idade", correspondente ao latino itas, que remete à noção de quantidade, segundo dicionário referenciado ao fim do texto), muito difundida e discutida atualmente nas articulações feministas, defende a ideia de irmandade e solidariedade absoluta entre as mulheres a partir de suas vivências e do compartilhamento da realidade de ser mulher; tal ideia é muito problematizada por segmentos do feminismo negro, classista e rural que adensam esse debate com o argumento da pluralidade das experiências femininas, do que é ser mulher e de como isso se que é ser mulher e de como isso se
expressa variavelmente em diferentes contextos e condições de relações sociais e de poder, seja entre mulheres e homens e entre as próprias mulheres. Dadas essas do texto, à ideia de solidariedade feminina, visto que me parece mais consensual, entre as próprias sujeitas protagonistas do feminismo, do que o uso do termo sororidade.

\section{Telephone Efect: a parceria fatal entre duas mulheres}

O vídeo de Telephone se inicia com a chegada de Lady Gaga à "Prision for Bitches" - que significa "Prisão para vadias/cadelas" em tradução livre - acompanhada de duas guardas. Lady Gaga fora condenada à prisão pelo assassinato de seu namorado, fato ocorrido no vídeo para a canção Paparazzi de 2009. Ela o mata e se auto denuncia sendo, nas cenas finais do videoclipe, levada pela polícia. Telephone (2010) tem aproximadamente 9 minutos e 30 segundos, e os primeiros 02:53min mostram a chegada e as interações estabelecidas entre Gaga e as demais detentas, bem como os conflitos entre estas.

A canção, no videoclipe, se inicia aos 02:47 min quando a cantora, então presa, recebe uma ligação de Beyonce e se inicia uma cena de canto e dança envolvida em dramaticidade, na qual Lady Gaga, acompanhada de quatro dançarinas trajando roupas íntimas, saltos altos e batons, começa a dançar entre as celas de um corredor. Em seguida, a transposição de imagens mostra rapidamente aos 04:14 min uma mensagem escrita por Gaga, em um celular afanado cenas antes, em agradecimento por tirá-la da cadeia. A mensagem no celular que está prestes a ser enviada diz, em tradução livre, "Obrigado por me tirar irmã!” (“Thanks for bailing me out Sista!"). Momentos depois Lady Gaga é solta e ouve de uma carcereira "Algum idiota pagou sua fiança", quando a cantora passa pelos portões de saída e entra numa caminhonete amarela. Entende-se que foi Beyonce quem pagou a fiança de Gaga, e ela já está a sua espera na saída do presídio.

É a partir dos 05:09 que as protagonistas da história estabelecem o diálogo que destrincha todo o filme: a conversa na caminhonete em movimento. Durante o trajeto as personagens deliberam sobre a parceria que estabelecerão em assassinar o companheiro de Beyonce, fato que culmina num homicídio em massa numa lanchonete a beira de uma estrada deserta. Recuperemos o diálogo:

Gaga: "Are you sure you wanna to do this, Honey Bee?" Beyonce: "What do you mean "Am I sure'?" Gaga: "You know what they say: once you kill a cow, 'gotta' make a Burger"

Beyonce: "you know gaga trust is like a mirror, you can fix it if it's

Gaga: "but you can still see the crack in the motherfucker's reflexion"

Aqui apreendemos toda a intencionalidade por traz da trama: Gaga questiona sua parceira sobre sua ciência do que estão prestes a fazer: pôr fim à vida de seu namorado, o que Gaga fizera em Paparazzi, motivo pelo qual foi presa. Ao receber resposta convicta, as duas seguem em direção à lanchonete onde Beyoncé se encontrará com seu namorado.

A forma com a qual Beyonce é tratada por seu amante quando de seu encontro, é encenada com gesto rude por parte dele em chama-la de vadia (sic) e questioná-la sobre seu atraso. Beyonce, demonstrando raiva, espera que ele se levante momento no qual ele assedia outra mulher em sua frente e troca empurrões com um homem - e acrescenta veneno ao seu café. Ao

Dossiê Literatura e Memória 
${ }^{2}$ Os óculos remetem aos personagens da Disney, Mickey Mouse e Minnie. retornar para seu acento e ingerir a bebida, ele tosse e mostra-se fisicamente diferente, afetado, mas a dose não é o bastante para matá-lo.

$\mathrm{Na}$ cozinha da lanchonete, Lady Gaga e sua equipe de auxiliares dançarinos compõem um balé cheio de dramatização enquanto envenenam toda a comida que será servida na lanchonete para os clientes. A dramaticidade envolvida na coreografia e nos movimentos dela e de seus dançarinos mostra um caráter ensandecido, com maquiagens pesadas e destaque para as expressões sérias ou irônicas dos olhos de todos. Ao jogar doses enormes de veneno sobre os pratos e acrescentar veneno ao mel, Gaga se expressa - facial e fisicamente - de modo muito similar à sua postura nos momentos anteriores de assassinar seu próprio namorado. A composição dos elementos no momento dessa cena, sugere desejo e intencionalidade de forma muito chamativa.

É ela quem leva os pratos à mesa do casal. Beyonce faz menção de pegar o vidro de mel, mas é interrompida de forma abrupta por seu namorado que o despeja em abundância sobre seu prato. Ao ingerir dos alimentos cobertos de mel, o personagem tem um ataque de tosse: conclui-se então a morte do companheiro de Beyonce que cai sobre seu próprio prato. A montagem do vídeo mostra, então, uma sucessão de imagens onde os demais clientes consomem seus pratos com volúpia. Após uma contagem regressiva feita por Lady Gaga, os clientes vão morrendo e Beyonce passa a portar os mesmos óculos ${ }^{2}$ usados por sua cúmplice ao assassinar seu namorado no vídeo de Paparazzi (2009).

Uma nova cena se inicia, na qual se tem, centralmente, as protagonistas e seus dançarinos envolvidos num frenesi dramático coreografado em meio a figurinos que remetem à bandeira dos Estados Unidos da América, mas que também chamam atenção pela semelhança com as roupas da Mulher Maravilha, personagem de histórias em quadrinhos. Mais adiante, enquanto as personagens principais saem perseguidas pela polícia, dirigindo a caminhonete Pussy Wagon, mostra-se uma chamada de reportagem na televisão, referindo-se ao homicídio em massa causado pelo então chamado "Telephone efect".

As duas mulheres estão juntas, agora em fuga por serem cúmplices de um assassinato. A cumplicidade gira em torno da morte de um homem (pivô de todo o ato) que fora anteriormente companheiro abusivo de uma das assassinas. Com tal morte, Beyonce aparenta ter se livrado do sofrimento que aquele homem a infligia assim como Gaga o fez, conforme seu videoclipe de Paparazzi (2009). Ambas puniram seus namorados por condutas ofensivas. Cabe agora retornar, muito brevemente, na videografia de Lady Gaga para capturar e manter em mente alguns acontecimentos no vídeo clipe de Paparazzi (2009).

Nele, Gaga mata seu namorado, pois ele tentara a destruir. Ao iniciar-se a trama de Paparazzi, mostra-se a cena de Lady Gaga no auge da fama, coberta de joias, dinheiro e champanhe, sendo amada por seu namorado. Ele a leva, então para a sacada, 
onde iniciam uma sessão de troca de carícias. Ao perceber que estão sendo fotografados por um paparazzi, seu namorado prossegue com o ato, demonstrando querer prolongar aquele momento de exposição. Lady Gaga recua e exige que ele pare, sendo, no entanto contrariada. Relutante, Gaga tenta afastá-lo com as mãos e ele usa da força contra ela. Gaga tenta afastá-lo, desta vez quebrando uma garrafa em sua cabeça. Enfurecido ele a joga da sacada.

$\mathrm{O}$ aspecto de seriedade e rigidez que acompanha a personagem de Lady Gaga, durante a maior parte do vídeo, só é quebrado quando ela envenena a bebida de seu namorado, causando sua morte. Ao vê-lo esmorecer e deixar o copo vazio cair, ela sorri e abre as abas de seus óculos, demonstrando satisfação. Sua expressão permanece a mesma até o momento em que faz uma ligação para a polícia confessando o assassinato. $\mathrm{O}$ semblante sorridente e vingativo se estende aos momentos em que ela é levada pela polícia, quando é intensamente fotografada pelas câmeras dos paparazzi.

Os dois videoclipes apresentam uma conexão muito significativa, não apenas por serem a continuação oficial um do outro. A ideia de enfrentar um homem abusivo numa relação surge nos dois como um tema central. Para Gaga, em 2009, tratava-se de se livrar de alguém que queria sua exposição, levá-la aos limites da fama, do dinheiro e destruí-la. Para Beyonce, em seguida, era uma questão de ser mal tratada, numa relação agressiva que encontrou seu fim na morte de uma das partes.
Lady Gaga aparece como figura fundamental, não apenas em sua história de enfrentamento, mas de ser parceira de outra mulher em livrar-se de um relacionamento abusivo. As duas experimentavam realidades minimamente semelhantes em seus relacionamentos, e ao livrar-se deles criam um evento ou fenômeno bastante interessante para se pensar relacionamentos, comunicações e articulações entre redes de mulheres.

\section{A solidariedade marcada por aspectos na materialidade fílmica}

A morte de ambos os namorados nos vídeos se mostra enquanto consequência da vontade de vingança de mulheres que tinham em seus relacionamentos, cada um à sua maneira, investidas que se mostravam abusivas por parte dos parceiros. $\mathrm{O}$ namorado de Lady Gaga em Paparazzi mostrava sua ganância por fama ao, forçosamente, expô-la aos cliques de um paparazzi, que registrava suas cenas de amor na sacada da mansão. Ele apresenta um caráter abusivo também por insistir com cariciais e investidas sexuais contra a vontade da namorada. Já o namorado de Beyoncé, por sua vez, era alvo do desejo de morte, por parte de sua companheira, por tratá-la mal, ofendendo-a, depreciando-a e controlando seus passos. Mostrava-se, também, invasivo com outras mulheres como na cena em que assedia, de forma sexual, uma garota. 
A vingança das duas contra esses homens se efetiva na morte. Beyonce só consegue saciar sua vontade de matar o homem que a oprime, em sua segunda tentativa, já que não obtém sucesso ao envenenar seu café. Lady Gaga também envenena seu namorado através de sua bebida, preparada por ela mesma; ele a toma em sua companhia, enquanto ela apresenta frieza e tranquilidade tomando uma xícara de chá.

Para além, talvez, do caráter vingativo que é explicitado nas relações entre estes personagens em ambos os vídeos, apresenta-nos formas de livramento e emancipação, ou, pelo menos podemos perceber assim se estendermos nossa leitura das relações entre as duas mulheres em questão e seus parceiros.

Podemos, portanto, pensar os assassinatos enquanto formas e expressões pelas quais duas mulheres se desvinculam de relacionamentos que acabam por tentar submetê-las e as tornarem subalternizadas, inferiorizadas e oprimidas. Elas conseguem, me parece, se desprender dessas relações e dessas posições, pela metáfora da eliminação através da morte. A morte se apresenta enquanto metáfora para pensarmos a finitude de um problema, como se as protagonistas pudessem "dar cabo" do problema, "dando cabo" da vida de seus parceiros.

Assim como poderíamos entender a eliminação de um problema através da retirada deste de nossos campos de experiência ou vivência, as protagonistas te Telephone - assim como de Paparazzi - fazem duplas retiradas: primeiro retiram os homens com quem se relacionavam de seus caminhos e, logo, de suas posições de opressores; Com os assassinatos e o consequente fim dos relacionamentos, retiram-se elas mesmas das posições de submissão que os ex-parceiros tentavam colocá-las.

Essas mortes têm uma centralidade que não pode ser negada dentro dessas materialidades que se apresentam enquanto pertinentes para abordar o caráter relacional de gênero envolvido. Mas outro aspecto é igualmente, talvez mais, importante para se pensar: a parceira e o apoio entre ambas as protagonistas de Telephone. Sozinha, Beyonce não matou seu namorado. Gaga também não foi liberada da cadeia sozinha. Nesses dois acontecimentos, um tipo de reciprocidade foi posta em questão e foi negociada. Uso o termo negociada não para me referir a trocas de bens materiais, mas de uma parceria solidaria entre as partes. Certamente orientadas por um conjunto de finalidades, e creio ser uma delas a solidariedade feminina.

Isso parece claro pelo fato de Beyonce demonstrar, a partir do que está explicitado nas cenas e diálogos do videoclipe, saber o motivo pelo qual Gaga foi presa, mesmo que isso não seja elaborado verbal e discursivamente durante os quase 10 minutos de filme. "You've been a very bad girl, Gaga", diz ela em suas primeiras falas, logo após pagar sua fiança. Momentos depois, Gaga demonstra ter conhecimento das intenções de Beyonce.

Podemos pensar que ambas sejam coniventes e/ou cumplices dos/com os crimes uma da outra, mas proponho e sugiro que seja, antes de tudo, um ato de solidariedade por parte de ambas as mulheres. Sou levado a perceber as coisas assim a partir 
do momento em que Beyonce paga a fiança de Gaga. Ela questiona Beyonce sobre sua certeza sobre o que estão prestes a fazer, e ao receber resposta afirmativa não pensa duas vezes em seguir adiante com o plano, mesmo que tivesse acabado de sair da prisão. Ao final, quando tudo está terminado e só lhes resta a caminhonete e a fuga, elas pactuam nunca mais voltar, comemorando seu plano bem sucedido. Estão, então, juntas, desde o apoio e a retirada de uma delas da cadeia, até às últimas consequências de um homicídio em massa. O apoio mútuo e a solidariedade se fazem bastante aparentes: solidariedade com as condições nas quais ambas estão, ou estiveram expostas, em seus relacionamentos, principalmente de Gaga para com Beyonce, por se mostrar disposta a se envolver num assassinato maior ainda em prol de sua parceira.

\section{Dialogando entre teorias e as materialidades}

A potencialidade dessas ideias se apresenta, através da união entre as mulheres protagonistas dessa história, na medida em que trazem em si e consigo o cerne de um importante debate feminista contemporâneo acerca da união feminina. O debate vem na performance. A ideia da solidariedade feminina vem na interação das duas intérpretes. Para além do lúdico e do fato de serem personagens, o imitiato representado ali são de mulheres que atuam enquanto mulheres e que acabam por trazer questões que dizem respeito à situação e às formas de representação dos discursos feministas sobre a solidariedade entre mulheres.

Falo em discurso, aqui, não necessariamente verbalizado nas falas e nos diálogos das interpretações, mas no sentido um tanto bourdieusiano de que o corpo traz e encerra em si uma história, que é reconhecível, passível de ser lida e entendida. Falo no sentido disposicional, no qual a historia individual, assim como a grupal ou coletiva, se localiza e sedimentaliza na materialidade corporal: é a estrutura social tornada estrutura mental (WACQUANT, 2007). Assim como os corpos e sujeitos, nas relações sociais fora das multimídias, dos produtos comunicacionais e das materialidades audiovisuais, os corpos representados nelas também trazem consigo uma série de signos e caracteres que nos permitem lê-los e localizá-los. Desta forma, o que considero aqui como discurso seriam as propriedades nos corpos representados das duas mulheres que estão unidas para pôr fim ao relacionamento abusivo de uma delas. O discurso vem do ato expressado pelo corpo.

Atrelado ao fato de que as personagens remetem e remontam a discursos, sugiro que está implícita a comunicação com o espectador, se considerarmos as materialidades audiovisuais enquanto formas de expressão, transmissão de ideias e comunicação. Mas a comunicação, nesse sentido, não estaria restrita na emissão e nos processos de assimilação e apreensão das mensagens de um material audiovisual qualquer. Minha intenção é provocar para uma comunicação que está nos corpos, na atuação 
das personagens, nesse vídeo em particular. Eles dizem algo e nós podemos apreender e entender o que eles estão dizendo em cena. Em outras palavras, podemos apreender e entender o que a cena ou o filme - diz por que conseguimos apreender e entender o que seus corpos nos dizem através de suas atuações.

Olívio Tavares de Araújo escreve, em 1963, o livro "Imitação, realidade e mimese" no qual ele pensa a arte como forma de linguagem e representação, considerando, ao longo de sua discussão, aspectos centrais no debate sobre a arte moderna e sua "incompreensibilidade" que por vezes a desvaloriza. Ao tratar, de forma mais atenta, da Arte enquanto linguagem, o autor considera que a Estética a reconhece como tal, em suas múltiplas formas, pelo processo comunicacional que se encerra na arte enquanto meio (ou fim), pelo qual, distinguindo-se das formas verbo-conceituais, existem dois momentos no processo de interlocução: o primeiro no qual a obra é concebida, chamada pelo autor de "autoexpressão" e o segundo, de "ressonância afetiva" que se expressa no sujeito que a contempla.

Para Araújo (1963), os meios pelos quais a arte seria capaz de produzir tal efeito se dão através de fenômenos correlatos que falam por aspectos, através da arte. Essa fala por aspectos se dá pelo caráter que compete à relação dialógica e comunicacional entre sujeito e arte de não possibilitar a percepção real e em totalidade. São nesses aspectos pelos quais a arte nos fala que somos capazes de assimilar discursos e dialogar com as obras artísticas, tais como as materialidades audiovisuais. Telephone fala, através de diversos aspectos, sobre união, afetividade, as relações entre homens e mulheres envolvidos em relacionamentos conturbados. Através destes aspectos é possível, então, que consigamos interpretar - a partir do que captamos dos significados e subjetividades envolvidas - as coisas por este viés, da solidariedade entre mulheres que se envolvem no sentido de findar uma situação abusiva dentro de seus relacionamentos afetivos.

Ao pensarmos sobre as possibilidades que uma obra, seja ela audiovisual, fílmica, uma pintura etc., tem para transmitir significados e subjetividades, somos levados a refletir sobre o que Gumbretch (2010) discute a respeito das potencialidades que as representações têm ao se projetarem a partir de presenças materiais anteriores. Seus argumentos indicam que a partir do exercício de atribuir sentidos e valores às representações e obras, constrói-se um movimento metafísico, capaz de transcender a própria materialidade da representação, extraindo dela mais do que, talvez, ela planejasse representar ao ser composta. Somos capazes, então, de extrair e absorver mais de uma obra do que sua expressão enquanto materialidade limitada possa conter, o que é possível devida a sua potência de significação.

Essa transposição das potencialidades interpretáveis e inteligíveis da materialidade, quando pensadas por Gumbretch (2010) na comunicação, permitem tratar a comunicação, dotada de conteúdo e sentindo, não apenas através da fala oral e escrita. A materialidade dos fenômenos e as percepções sobre a matéria seriam também, segundo esse autor, capazes de afetar nossos 
sentidos e gerar comunicação, transmitir mensagens dotadas de sentido. Essas ideias nos permitem pensar as materialidades audiovisuais enquanto formas de transmissão e transferência de mensagens e discursos, que podem promover sociabilidades e, até, socializações ao considerarmos o compartilhamento das interpretações de sujeitos expectadores dessas materialidades. Recebemos através de materialidades audiovisuais, valores, ideias, objetivos e subjetividades, elementos que são significativos e atingem nossas capacidades sensoriais e cognitivas, o que tem impactos dos mais variados tipos e ordens. A alteração de estados de consciências, percepções e identidades é possível se pensamos a potencialidade de tais materialidades fílmicas, como Telephone, na mídia e na indústria cultural contemporânea, em produzir esses efeitos citados anteriormente.

Procuro dialogar com esses autores intentando aproximar o debate sobre a potencialidade da arte e das materialidades audiovisuais, de modo geral, com o vídeo que estimula toda essa discussão. Tal vídeo tem a capacidade de sugerir essa interpretação da solidariedade feminina, bem como fomentar mais debates acerca dessa questão, mas também é potente no sentido de influenciar tal prática no cotidiano social e experienciável das pessoas, principalmente entre mulheres, a partir dos processos de assimilação e aprendizagem por meio das materialidades audiovisuais. Evitando maiores extrapolações, proponho que nos atenhamos à popularização que os discursos de solidariedade feminina e inclusive sua expressão mais abrangente, a sororidade, vêm ganhando.

Podemos considerar que essa popularização esteja sendo beneficiada pelos avanços dos meios de disseminação e compartilhamento de informações e debates (sobre gênero, sexualidade, feminismo e solidariedade entre mulheres), isto é, os blogs na web, os canais de interação via vídeo, seja por vlogs ou canais no YouTube, mas cabe o questionamento: qual seria o alcance e a potência de Telephone para estimular todos esses debates? Quais os alcances e potencialidades de outras materialidades que abordem questões semelhantes, tais quais o protagonismo exclusivo de mulheres em filmes ou videoclipes e sua união - ou não rivalidade, pelo menos - em fazer pensar e discutir sobre solidariedade feminina? Qual seria a participação e influência das materialidades audiovisuais, de grande circulação atualmente, para pensarmos a comunicação potente de (i) compartilhamento de ideias, (ii) tomada de consciência, (iii) influência na experiência particular das pessoas etc.? Quais as relações entre a produção das materialidades audiovisuais que abordem tais questões da união e solidariedade feminina e o aumento - ou popularização - dos discursos de solidariedade feminina e sororidade nos mais diversos meios de comunicação via web, redes sociais e coletivos de movimentos sociais atualmente? Essas são todas questões que não foram ou serão esmiuçadas ou respondidas neste ensaio, mas é fundamental 
3 2014, Walt Disney Animation Studio.

4 2012, Pixar Animation Studio, originalmente Brave.

2014 Walt Disnley Pictures, originalmente Maleficent.

${ }^{6} \mathrm{O}$ objetivo não é generalizar ou criar um padrão de finais de filmes, mas há uma longa tradição de enredos cinematográficos e de produções de videoclipes em que há uma centralidade dos relacionamentos entre homens $\mathrm{e}$ mulheres ante a união entre mulheres, sejam estas parceiras afetivas ou não. pensar a transversalidade dessas questões na atualidade e as suas relações com o videoclipe de Telephone.

Recorrentemente tem se produzido, no cinema, filmes com finais felizes que não se dão da forma mais costumeira, onde um homem e uma mulher terminam juntos ou apaixonados, reproduzindo lógicas heteronormativas, ou como o casamento, por exemplo. Destaque para recentes produções como as animações Frozen $^{3}$ e Valente $^{4}$, e a adaptação Malévola ${ }^{5}$ da clássica $A$ bela adormecida que, por mais que não tratem de finais tão inesperados em suas tramas, carregam em si um sentido quase que subversivo do que é popularmente conhecido: estas obras mostram finais nos quais o que prevalece são a união entre as personagens femininas em primeiro plano. Nestas produções, assim como em Telephone (2010), as protagonistas permanecem juntas, e unidas ao fim do filme. Mesmo que tramas com essa abordagem existam ao longo de todos os anos de produção cinematográfica e fílmica, esses desfechos não são os mais comuns, nos quais a rivalidade entre mulheres, principalmente quando ambas estão envolvidas com um homem, geralmente prevalece ao final, onde apenas uma é vencedora ${ }^{6}$.

Esses questionamentos e reflexões surgem à medida que pensamos sobre os desdobramentos miméticos entre o produto artístico e aquilo ao qual ele se referencia. Algo que chama muita atenção é uma possível dialógica entre o aumento dos discursos e práticas feministas sobre a solidariedade feminina por um lado, e por outro, essas produções audiovisuais que surgem com frequência notável nos últimos anos e que tem em seus enredos a união entre as mulheres como um elemento fundamental. Telephone, ao retratar a relação entre Lady Gaga e Beyonce, é mais um exemplo de vários outros onde há uma incorporação das ideias de solidariedade feminina, que pode acabar por influenciar mais solidariedades entre mulheres na vida cotidiana, nas experiências matérias das sujeitas. Há aí algo que merece ser discutido com mais recursos: quais as interpenetrações entre a vida cotidiana e a produção de materiais fílmicos audiovisuais? Aponto para duplas incursões miméticas que vão a direções similares: a vida material e cotidiana de discursos de militância influencia a consciência daqueles que planejaram uma obra tal qual Telephone, bem como as outras citadas, da mesma forma que essas materialidades têm o potencial de influenciar as consciências dos seus expectadores, ou suas expectadoras. Seria de certa forma, retomar o debate da arte imitando a vida, e a vida imitando a arte, porém de forma mais sútil, sem nos limitar a pensar esse duplo movimento enquanto imitações.

A mímesis é reconhecida por Lima (1995) enquanto um elemento que não se limita a imitação ou a cópia, assim como, em outra obra (2003) ele a pensa como um ato mimético dialético: algo permanente que não nega o transformado e o transformado que não elimina o que é permanente. Suas ideias permitem que interpretemos a obra mimética como sendo geradora, antes de imitadora. A partir disso, somos levados a considerar ainda mais a dialógica entre as produções audiovisuais/cinematográficas atuais 
e os discursos feministas. Ao mesmo tempo em que são potentes para inflamar os discursos feministas de solidariedade feminina, essas obras são miméticas do discurso e do real experimentado cotidianamente por feministas que defendem as ideias de solidariedade feminina.

Procuro pensar e fazer pensar como se ocorressem processos de assimilação entre ideias presentes nas produções audiovisuais, que são consumidas hoje em dia e que são possíveis geradores de consciência, mas ao mesmo tempo são geradas pelas próprias consciências e críticas feministas da realidade e da solidariedade feminina - que afetam as produções audiovisuais de formas bastante variadas.

\section{Considerações finais}

Neste ensaio, busquei, tendo como ponto de partida a parceria entre as cantoras estadunidenses Lady Gaga e Beyonce, refletir sobre as possíveis relações - ou movimentos miméticos entre as produções audiovisuais e os discursos de incentivo da solidariedade feminina. Tal discurso não aparece expresso materialmente em falas e textos, mas é possível de apreendê-lo considerando as atuações, os afetos e as histórias materializadas nas personagens do videoclipe. A partir daí, questiono as penetrações da vida material nas produções fílmicas e as possíveis penetrações dos filmes nas experiências cotidianas de coletivos feministas e articulações em diversos canais de comunicação via web ou presenciais.

Meu ponto reflexivo é de que, mesmo que não haja a defesa expressa na narrativa discursiva das, e entre as, sobre o apoio mútuo entre mulheres ou sobre a solidariedade entre as mesmas, a ideia está presente e se faz reconhecível/inteligível. Ainda que a trama se desenvolva sem o uso do artificio discursivo literal (falas de solidariedade entre mulheres) nota-se a presença da união entre duas mulheres, que é levada até as últimas consequências, quando estas se tornam inimigas da opinião pública, fugitivas e procuradas. Lady Gaga não promete verbalmente à sua parceira que a apoiará e que permanecerá solidaria em sua defesa, mas assim como o corpo encerra a historia, o corpo pode levar o discurso e através da linguagem do vídeo e da atuação corpo-teatral das personagens somos levados a ideia de que o suporte à sua amiga (principalmente levada frente a preponderância masculina) prevalecerá.

A trama de Telephone (2010) se mostra como forma e expressão de protagonismo feminino, nos quais as mulheres são o objeto do cuidado uma da outra. Essa ideia escapa à forma canônica e cristalizada de se pensar as representações de feminilidade no cinema e no audiovisual como uma tendência sempre de formar par com o masculino. Busquei mostrar que, o protagonismo feminino em Telephone (2010), assim como nas demais histórias brevemente citadas, não se dá apenas pelo protagonismo do videoclipe ser de duas personagens mulheres, 
mas pelo fato de a história colocar as figuras femininas como objeto do cuidado e afetividade centrais, consolidando a união entre as mesmas.

Podemos considerar que há, ainda, uma relação de desdobramentos entre a mimesis, presente na composição da historia de Telephone (2010), ao incorporar em sua materialidade a realidade e a sensibilidade do discurso feminista sobre solidariedade entre mulheres, e que é, ao mesmo tempo, possibilidade de que se criem os processos de criação e tomada de consciência, pressupostos nos processos comunicacionais que acompanham as produções audiovisuais e artísticas.

\section{Referências bibliográficas}

ARAÚJO, Olívio Tavares, de; Imitação, Realidade e Mimese Problemas da Arte Contemporânea. MG, Editora da Universidade de Minas Gerais, Belo Horizonte 1963.

BOURDIEU, Pierre. O Senso Prático. Petrópolis, RJ: Vozes, 2011.

FARIA, Ernesto. Dicionário Latino-Português. Belo Horizonte: Livraria Garnier, 2003.

GUMBRETCH, Hans. Produção de Presença: o que o sentido não consegue transmitir. Rio de Janeiro: PUC-Rio, 2010

LIMA, Luiz Costa. Vida e Mímesis. São Paulo, Editora 34, 1995.

LIMA, Luiz Costa. Mimesis e Modernidade: formas das sombras. São Paulo: Paz e Terra, 2003.
WACQUANT, Loic. "Notas para esclarecer a noção de habitus". RBSE, 6(16), abril de 2007.

$--$

Lady Gaga - Telephone ft. Beyoncé. 2010. Telephone. [online]. [Visto em 25/08/2015]. Disponível em: https://www.youtube.com/watch?v=EVBsypHzF3U

Lady Gaga - Paparazzi. 2009. Paparazzi [online]. [Visto em 25/08/2015]. Disponível

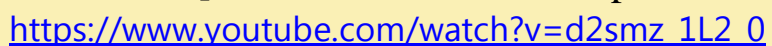

